\title{
Analisa Sistem Instalasi Listrik Dan Pembagian Daya Di P.T Kereta Api Indonesia Persero (Studi Kasus Stasiun Tebing Tinggi)
}

\author{
Cholish $^{1}$, Ilham Andrea ${ }^{2}$, Abdullah ${ }^{1}$, Moh. Zainul Haq ${ }^{1}$, Sinta Marito Siagian ${ }^{1}$ \\ ${ }^{1}$ Program Studi Teknik Listrik, Jurusan Teknik Elektro \\ Politeknik Negeri Medan \\ Jl. Almamater No.1, Padang Bulan, Kota Medan, Sumatera Utara Telp. (061) 8210436 Kode pos 20155 \\ ${ }^{2}$ Program Studi Teknik Elektro, Fakultas Teknik \\ Universitas Muhammadiyah Sumatera Utara (UMSU) \\ Jl. Kapten Muchtar Basri,BA No. 03 Medan Telp. (061) 6622400 ex. 12 Kode pos 20238 \\ e-mail: cholish@polmed.ac.id
}

\begin{abstract}
Abstrak - Kehidupan pesatnya perkembangan zaman dari tahun ke tahun membuat fasilitas teknologi semakin canggih, salah satunya ialah cahaya penerangan. Setiap dunia perusahaan memiliki cahaya penerangan pada semua sudut ruangan dengan guna memberikan penjelasan dalam melihat melakukan sebuah aktivitas. Cahaya penerangan adalah salah satu komponen yang penting dalam merencanakan suatu aktivitas agar mendapatkan suatu tujuan tertentu. Pencahayaan pada suatu ruangan jika dilihat dari kualitas adalah berupa kuat penerangan atau tingkat iluminasi yang dibutuhkan dimana untuk jenis kegiatan yang berbeda akan memerlukan tingkat iluminasi yang berbeda-beda pula. Melalui hasil penelitian intensistas cahaya penerangan ruang dengan menggunakan Standar SNI 16-7062-2004 serta menghitung energi listrik yang digunakannya. Pengukuran intensitas penerangan diukur menggunakan alat ukur Lux Meter. Pengukuran dilakukan langsung pada saat observasi dilapangan. Ruangan sesuai standar persyaratan kesehatan lingkungan kerja perkantoran dan industri mempunyai fasilitas Intensitas Penerangan (E) dengan tujuan mengetahui titik-titik pencahayaan lampu $(\mathrm{N})$ dimana saja yang digunakan disetiap ruangan serta melakukan pengujian pada untuk mencari hasil ukuran dari item pencahayaan. Dan yang paling utama tujuannya yaitu agar pegawai dilingkungan kerja tersebut dapat beraktivitas dalam bekerja dengan aman dan nyaman.
\end{abstract}

Kata kunci : instalasi listrik, intensitas cahaya, menentukan sistem lampu.

\begin{abstract}
The rapid development of the times from year to year has made technological facilities more sophisticated, one of which is lighting. Every corporate world has lighting in all corners of the room in order to provide an explanation for seeing doing an activity. Lighting is an important component in planning an activity in order to achieve a specific goal. Lighting in a room, when viewed from quality, is in the form of strong lighting or the level of illumination needed, which for different types of activities will require different levels of illumination. Through the results of research on light intensity of space lighting using the SNI Standard 16-7062-2004 and calculating the electrical energy it uses. Measurement of light intensity is measured using a Lux Meter measuring instrument. Measurements are made directly during field observations. Rooms according to standard health requirements for office and industrial work environments have Illumination Intensity (E) facilities with the aim of knowing which lighting points (N) are used in each room and conducting tests to find the size results of lighting items. And the most important goal is that employees in the work environment can work safely and comfortably.
\end{abstract}

Keywords : $\quad$ electrical installation, light intensity, determine the lighting system.

\section{PENDAHULUAN}

PT KAI Stasiun Tebing Tinggi merupakan Badan Usaha Milik Negara yang menyediakan, mengatur, dan mengurus jasa angkutan kereta api di Indonesia. Stasiun Tebing Tinggi bertempat di Jl. Mayjen Sutoyo Padang Hilir, Kota Tebing Tinggi Sumatera Utara. Stasiun Tebing Tinggi ini ialah stasiun kereta api kelas I yang terletak pada ketinggian $+21,50$ meter yang termasuk dalam Divisi Regional I Sumatera Utara dan Aceh. Stasiun ini memiliki enam jalur kereta api dengan jalur 1 merupakan sepur lurus dari dan ke arah
Medan, kemudian jalur 2 merupakan sepur lurus dari dan ke arah Siantar, dan jalur 3 merupakan sepur lurus dari dan ke arah Kisaran. Stasiun ini terdapat dipo mekanik yang menjadi markas semua peralatan dan kereta mekanik seperti mesin pecok, pengatur balast, dan kereta penolong. Di samping itu, stasiun ini juga terdapat satu-satunya pemutar rel yang tersisa di Divisi Regional I Sumatera Utara dan Aceh. Uniknya, meja pemutar ini dioperasikan dengan cara diengkol, bukan didorong. Di sebelah pemutar rel ini masih terdapat sebuah los bundar 8 pintu yang juga 
merupakan sisa peninggalan Deli Spoorweg Maatschappij.

Di stasiun tebing tinggi saat ini sedang melakukan peremajaan atau pemulihan instalasi listrik yang nanti agar dapat berjalan dengan baik dan optimal lagi, di lansir dari beberapa bulan belakangan sering terjadinya drop tegangan, berantakan kabel-kabel instalasi listrik pada stasiun tersebut dan sering padamnya listrik yang tidak tentu waktunya, dan ada beberapa ruangan yang listriknya nyala dan ada juga beberapa ruangan yang tidak menyala, hal ini dapat mengganggu kenyamanan dan keamanan penumpang yang berada di sekitar stasiun tebing tinggi, disini kami mencoba melakukan renovasi sistem instalasi listrik yang baru. Perkembangan teknologi yang semakin modern, kebutuhan akan listrik semakin tinggi, hal ini membuktikan bahwa semua lapisan masyarakat dari perkantoran hingga rumah tangga menggunakan energi listrik. Pemanfaatan energi listrik agar tidak menimbulkan arus hubung singkat saat penggunaan perlu adanya pemasangan instalasi listrik yang benar dan aman sesuai standar berdasarkan peraturan yang berlaku seperti pengaman arus listrik, diamater penghantar dan sebagainya agar tidak memicu hal-hal yang dapat merugikan dan ketidaknyamanan pengguna fasilitas gedung tersebut.

Di dalam Stasiun Tebing Tinggi terdapat gedung beserta ruangan-ruangan untuk para pimpinan dan pegawai-pegawai KAI yang sesuai dengan bidangbidang pekerja tertentu. Pada setiap gedung mempunyai ruangan- ruangan dengan tujuan agar memperlancarnya fungsi perusahaan kereta api dan keamanan pada penumpang, mulai dari ruangan sistem kontrol, sistem pemantau, IT, bagian teknisi dan mekanik mesin, rungan pimpinan perusahaan, ruangan tunggu penumpang, sampai dengan bagian dapur. Di dalam ruangan terdapat alat penerang pencahayaan yang gunanya untuk menyinari suasana di dalam ruangan agar para penempat dapat jelas dalam beraktifitas. Pencahayan berikut memiliki jenisjenis lampu yang berbeda-beda, sesuai dengan fungsi yang cocok pada ruangan tersebut. Apabila ruangan memiliki pencahayaan yang memadai dan tidak memadai akan mendapatkan efek positif dan negatif pada orang yang berada ditempat. Pencahayaan yang memadai menyebabkan kelainan pada indra penglihatan dan kesilauan yang dapat menimbulkan kecelakaan kerja. Pencahayaan yang kurang memadai dapat menyebabkan ganguan kesehatan pada pekerja, salah satunya adalah kelelahan mata. Selain itu, kelelahan mata timbul sebagai stress intensif pada fungsi-fungsi mata seperti terhadap otot-otot akomodasi pada pekerja yang perlu pengamatan secara teliti atau pada retina sebagai ketidaktepatan bahwa intensitas pencahayaan pada setiap ruang kerja baik pencahayaan umum maupun pencahayaan lokal tidak memenuhi standar, bahwasanya terdapat sebagian besar responden mengalami keluhan kelelahan mata dan paling banyak mengalami keluhan okular pada tingkat penerangan. Oleh karena itu, pimpinan seharusnya memperhatikan para konsumen dan pekerja dalam melakukan aktifitas pada setiap ruangan yang memiliki daya pencahayan yang lebih maupun kurang dalam sistem penerangan.

\section{TINJAUAN PUSTAKA}

Sistem Instalasi Listrik

Sistem instalasi listrik adalah suatu proses penyaluran daya listrik yang dibangkitkan dari sumber tenaga listrik ke alat-alat listrik atau beban yang disesuaikan dengan ketentuan yang telah ditetapkan dalam peraturan dan standar listrik yang ada, misalnya IEC (International Electrotecnical Commission), PUIL (Persyaratan Umum Instalasi Listrik), IEEE, SPLN, dan sebagainya.

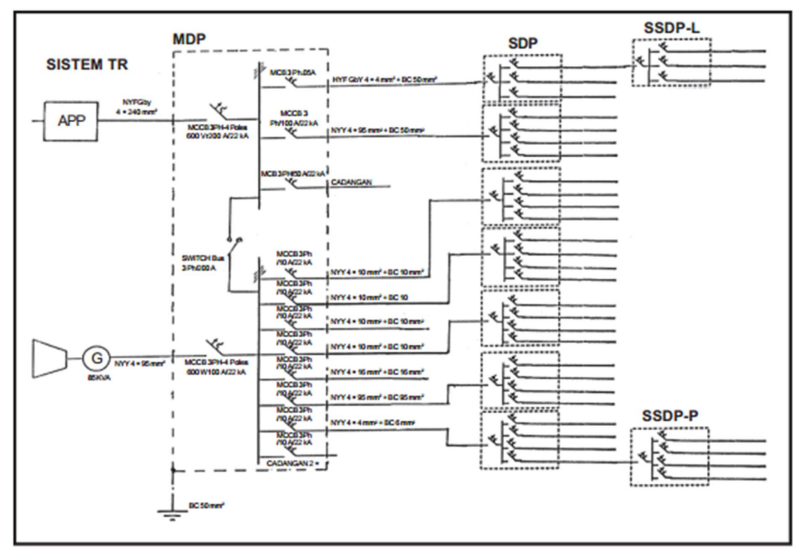

Gambar 1 Diagram Garis Satu Instalasi Listrik

Bagian-bagian pada instalasi listrik :

TM : Tegangan Menengah (Besarnya tegangan sekitar 20.000 Volt atau 20KV)

TR : Tegangan Rendah (besarnya tegangan sekitar 220/380 Volt)

APP : Alat Pembatas dan Pengukur

MDP : Main Distribution Panel (panel utama)

SDP : Sub Distribution Panel (panel cabang)

SSDP : Sub-Sub Distribution Panel (panel beban)

Sistem instalasi listrik pada dasarnya dapat dibagi menjadi 2 bagian :

1. Instalasi Listrik Pembangkit Tenaga Diesel

2. Instalasi Listrik Penerangan

Instalasi Listrik Pembangkit Tenaga Diesel

Instalasi listrik tenaga diesel ialah instalasi yang menggunakan mesin diesel sebagai Prime Mover. Prime mover merupakan peralatan yang mempunyai fungsi menghasilkan energi mekanis yang diperlukan untuk memutar rotor generator. PLTD merupakan suatu instalasi pembangkit listrik yang terdiri dari suatu unit pembangkit dan sarana pembangkitan. 
Pada mesin Diesel Energi Bahan bakar diubah menjadi energi mekanik dengan proses pembakaran di dalam mesin itu sendiri.

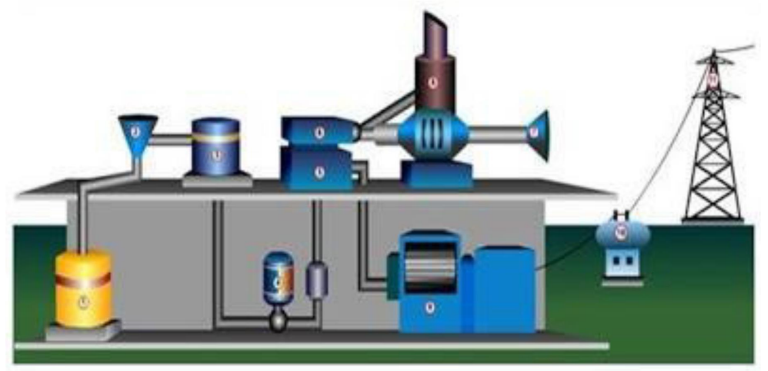

Gambar 2 Bentuk dan Bagian Alat Instalasi

Pembangkit Listrik Tenaga Diesel diesel :

Bagian-bagian pada alat instalasi listrik tenaga

1. Tangki penyimpanan bahan bakar.

2. Penyaring bahan bakar.

3. Tangki penyimpanan bahan bakar sementara

4. Pengabut.

5. Mesin diesel.

6. Turbo charger.

7. Penyaring gas pembuangan.

8. Tempat pembuangan gas (bahan bakar yang disaring).

9. Generator.

10. Trafo.

11. Saluran transmisi

Instalasi Listrik Penerangan

Instalasi listrik penerangan ada 2 (dua) macam, yaitu :

1. Instalasi di dalam gedung

2. Instalasi di luar gedung

Instalasi di dalam gedung adalah instalasi listrik di dalam bangunan gedung (termasuk untuk penerangan, teras dan lain-lain) sedangkan instalasi di luar bangunan gedung (termasuk disini adalah penerangan halaman, taman, jalan penerangan papan nama dan lain-lain). Tujuan utama dari instalasi listrik penerangan adalah untuk memberikan kenyamanan terhadap keadaan yang memerlukan ketelitian maka diperlukan penerangan yang mempunyai kuat penerangan besar sedangkan untuk pekerjaanpekerjaan yang memerlukan ketelitian tidak perlu menggunakan penerangan yang mempunyai penerangan besar. Sedangan instalasi di luar gedung adalah instalasi yang digunakan untuk menjalankan mesin-mesin listrik termasuk disini adalah instalasi untuk melayani motor-motor listrik di pabrik, pompa air, dan lain-lain, pada mesin-mesin.

\section{METODE}

Waktu penelitian di mulai tanggal 24 November 2019 hingga 2 Maret 2020, dan tempat penelitian dilakukan di Stasiun Tebing Tinggi. Perencanaan instalasi dan pengukuran intensitas cahaya juga dilakukan di Stasiun Tebing Tinggi.

\section{Alat dan Bahan Penelitian}

\section{Lux Meter}

Lux meter adalah sebuah alat yang mampu mengetahui serta mengukur seberapa besarnya intensitas cahaya yang berada disuatu tempat. Tentunya bukan rahasia umum lagi jika setiap tempat memiliki ukuran penerangan yang berbeda-beda, hal tersebut ditentukan oleh faktor kebutuhan yang melekat. Lux Meter berfungsi sebagai alat pengukur intensitas cahaya yang tersebar didalam suatu tempat. Penciptaan alat ukur cahaya tersebut dilatarabelakangi kesadaran kebutuhan cahaya yang berbeda-beda ditiap rungan, misalnya pada ruang kerja. Pencahayaan yang ada diruang kerja tentunya harus lebih kurang dari pada ruangan khusus.

\section{Material Instalasi Listrik}

Kabel Listrik

Kabel listrik berfungsi sebagai konduktor atau penghantar tegangan, arus dan daya listrik dari pembangkit ketitik-titik beban. Berdasarkan jenis pemasangan, kabel jenis kabel yang ada dipasaran terbagi menjadi dua macam kabel pasangan dalam dan kabel pasangan luar. Berdasarkan ekakuannya kabel dibedakan kabel fleksibel dan kabel kaku. Umumnya kabel yang dipasang dalam gedung, mempunyai sifatnya permanen penggunakan jenis kabel NYM. Dan jenis kabel NYY untuk dipasang diluar bangunan. Besar kecil ukuran kebel listrik yang akan dipasang tergantung dari beban yang akan digunakan, makin besar daya listrik yang dipakai maka penampang ukuran kabel juga harus lebih besar. Umumnya kabel mempunyai Standar Kemampuan Hantar Arus. Instalasi jala-jala listrik di Indonesia berpedoman pada Standar Nasional Indonesia[SNI] tahun 2000, Kemampuan Hantar Arus konduktor kabel tertuang pada Tabel 1.

Tabel 1 Kuat Hantar Arus

\begin{tabular}{|c|c|c|c|c|c|c|c|}
\hline \multirow{4}{*}{$\begin{array}{l}\text { Jenis } \\
\text { Kabel }\end{array}$} & \multirow{4}{*}{\begin{tabular}{|c|}
$\begin{array}{c}\text { Luas } \\
\text { Penampung }\end{array}$ \\
{$\left[\mathrm{mm}^{2}\right]$} \\
\end{tabular}} & \multicolumn{6}{|c|}{ KHA terus menerus } \\
\hline & & \multicolumn{2}{|c|}{ Berinti tunggal } & \multicolumn{2}{|c|}{ Berinti dua } & \multicolumn{2}{|c|}{ Berinti tiga dan empa } \\
\hline & & di tanah & di udara & di tanah & di udara & di tanah & di udara \\
\hline & & {$[\mathrm{A}]$} & {$[\mathrm{A}]$} & {$[\mathrm{A}]$} & {$[\mathrm{A}]$} & {$[\mathrm{A}]$} & {$[\mathrm{A}]$} \\
\hline & 1,5 & 40 & 26 & 31 & 20 & 26 & 18.5 \\
\hline NYY & 2,5 & 54 & 35 & 41 & 27 & 34 & 25 \\
\hline NYBY & 4 & 70 & 46 & 54 & 37 & 44 & 34 \\
\hline $\begin{array}{c}\text { BYFG } \\
\text { bY }\end{array}$ & 6 & 90 & 58 & 68 & 48 & 56 & 43 \\
\hline $\begin{array}{c}\text { BYRG } \\
\text { bY }\end{array}$ & 10 & 122 & 79 & 92 & 66 & 75 & 60 \\
\hline NYCY & 16 & 160 & 105 & 121 & 89 & 98 & 80 \\
\hline NYC & 25 & 206 & 140 & 153 & 118 & 128 & 106 \\
\hline
\end{tabular}




\begin{tabular}{|c|c|c|c|c|c|c|c|}
\hline \multirow{2}{*}{$\begin{array}{c}\text { Jenis } \\
\text { Kabel }\end{array}$} & \begin{tabular}{c} 
Luas \\
\cline { 3 - 8 }
\end{tabular} & $\begin{array}{c}\text { Penampung } \\
{\left[\mathrm{mm}^{2}\right]}\end{array}$ & \multicolumn{2}{|c|}{ Berinti tunggal } & \multicolumn{2}{|c|}{ Berinti dua } & Berinti tiga dan empat \\
\cline { 3 - 8 } & {$[\mathrm{A}]$} & {$[\mathrm{A}]$} & {$[\mathrm{A}]$} & {$[\mathrm{A}]$} & {$[\mathrm{A}]$} & {$[\mathrm{A}]$} \\
\hline WY & & & & & & & \\
\hline NYSY & 35 & 249 & 174 & 187 & 145 & 157 & 131 \\
\hline $\begin{array}{c}\text { NYCE } \\
\text { Y }\end{array}$ & 50 & 296 & 212 & 222 & 179 & 185 & 159 \\
\hline $\begin{array}{c}\text { NYSE } \\
\text { Y }\end{array}$ & 70 & 365 & 269 & 272 & 224 & 228 & 202 \\
\hline $\begin{array}{c}\text { NYHS } \\
\text { Y }\end{array}$ & 95 & 438 & 331 & 328 & 271 & 275 & 244 \\
\hline $\begin{array}{c}\text { NYK } \\
\text { Y }\end{array}$ & 120 & 499 & 386 & 375 & 314 & 313 & 282 \\
\hline $\begin{array}{c}\text { NYKB } \\
\text { Y }\end{array}$ & 150 & 561 & 442 & 419 & 361 & 353 & 324 \\
\hline $\begin{array}{c}\text { NYKF } \\
\text { GBY }\end{array}$ & 185 & 637 & 511 & 475 & 412 & 399 & 371 \\
\hline $\begin{array}{c}\text { NYKR } \\
\text { GbY }\end{array}$ & 240 & 743 & 612 & 550 & 484 & 464 & 436 \\
\hline & 300 & 843 & 707 & 525 & 590 & 524 & 481 \\
\hline & 400 & 986 & 859 & 605 & 710 & 600 & 560 \\
\hline & 500 & 1125 & 1000 & - & - & - & - \\
\hline
\end{tabular}

Nilai-nilai yang tercatum pada Tabel 2. masih kurang tepat maka diperlukan koreksi, untuk mendapatkan nilai mendekati tepat nilai pada tabel 1 dikalikan dengan nilai koreksi yang dimuat dalam Tabel 2.

Tabel 2 Faktor koreksi untuk KHA

\begin{tabular}{|c|c|c|c|c|c|c|}
\hline $\begin{array}{c}\text { Suhu } \\
\text { Keliling }\end{array}$ & $15^{\circ} \mathrm{C}$ & $20^{\circ} \mathrm{C}$ & $25^{\circ} \mathrm{C}$ & $30^{\circ} \mathrm{C}$ & $35^{\circ} \mathrm{C}$ & $40^{\circ} \mathrm{C}$ \\
\hline $\begin{array}{c}\text { Faktor } \\
\text { koreksi }\end{array}$ & 1.18 & 1.12 & 1.07 & 1 & 0.94 & 0.87 \\
\hline
\end{tabular}

\section{$\mathrm{MCB}$}

MCB sering disebut juga pengaman otomatis. Pengaman otomatis ini memutuskan sirkit secara otomatis apabila arusnya melebihi setting dari MCB tersebut. Pengaman otomatis dapat langsung dioperasikan kembali setelah mengalami pemutusan (trip) akibat adanya gangguan arus hubung singkat dan beban lebih.

\section{Jenis-Jenis MCB}

30 (Setiawan HV. 1981). Berdasarkan waktu pemutusannya, pengaman-pengaman otomatis dapat terbagi atas Otomat-L, Otoma-H, dan Otomat-G.

a). Otomat-L (Untuk Hantaran)

Pada Otomat jenis ini pengaman termisnya disesuaikan dengan meningkatnya suhu hantaran. Apabila terjadi beban lebih dan suhu hantarannya melebihi suatu nilai tertentu, elemen dwi logamnya akan memutuskan arusnya. Kalau terjadi hubung singkat, arusnya diputuskan oleh pengaman elekromagnetiknya. Untuk arus bolak-balik yang sama dengan 4 In-6 In dan arus searah yang sama dengan 8 In pemutusan arusnya berlangsug dalam waktu 0.2 sekon.

b). Otomat-H (Untuk Instalasi Rumah)

Secara termis jenis ini sama dengan Otomat-L. Tetapi pengaman elektromagnetiknya memutuskan dalam waktu 0,2 sekon, jika arusnya sama dengan 2,5 In-3 In untuk arus bolak-balik atau sama dengan 4 In untuk arus searah. Jenis Otomat ini digunakan untuk instalasi rumah. Pada instalasi rumah, arus gangguan yang rendah pun harus diputuskan dengan cepat. Jadi kalau terjadi gangguan tanah, bagian-bagian yang terbuat dari logam tidak akan lama bertegangan.

c). Otomat-G

Jenis Otomat ini digunakan untuk mengamankan motor-motor listrik kecil untuk arus bolak-balik atau arus searah, alat-alat listrik dan juga rangkaian akhir besar untuk penerangan, misalnya penerangan pabrik. Pengaman elektromagnetiknya berfungsi pada $8 \mathrm{In}$ 11 In untuk arus bolak-balik atau pada 14 In untuk arus searah. Kontak-kontak sakelarnya dan ruang pemadam busur apinya memiliki konstruksi khusus. Karena itu jenis Otomat ini dapat memutuskan arus hubung singkat yang besar, yaitu hingga $1500 \mathrm{~A}$.

\section{Cara kerja $\mathrm{MCB}$}

Cara kerja MCB sebagai berikut:

a.Thermis; prinsip kerjanya berdasarkan pada pemuaian atau pemutusan dua jenis logam yang koefisien jenisnya berbeda. Kedua jenis logam tersebut dilas jadi satu keping (bimetal) dan dihubungkan dengan kawat arus. Jika arus yang melalui bimetal tersebut melebihi arus nominal yang diperkenankan maka bimetal tersebut akan melengkung dan memutuskan aliran listrik.

b.Magnetik; prinsip kerjanya adalah memanfaatkan arus hubung singkat yang cukup besar untuk menarik sakelar mekanik dengan prinsip induksi elektromagnetis. Semakin besar arus hubung singkat, maka semakin besar gaya yang menggerakkan sakelar tersebut sehingga lebih cepat memutuskan rangkaian listrik dan gagang operasi akan kembali ke posisi off. Busur api yang terjadi masuk ke dalam ruangan yang berbentuk pelat-pelat, tempat busur api dipisahkan, didinginkan dan dipadamkan dengan cepat.

\section{$\mathrm{MCCB}$}

MCCB atau Moulded Case Circuit Breaker adalah alat pengaman yang berfungsi sebagai pengamanan terhadap arus hubung singkat dan arus beban lebih. MCCB memiliki rating arus yang relatif tinggi dan dapat disetting sesuai kebutuhan. Spesifikasi MCCB pada umumnya dibagi dalam 3 parameter operasi yang terdiri dari:

a. Ue (tegangan kerja), spesifikasi standar MCCB digambarkan sebagai berikut: $\mathrm{e}=250 \mathrm{~V}$ dan $660 \mathrm{~V}$ b. Ie (arus kerja), spesifikasi standar MCCB digambarkan sebagai berikut: $\mathrm{Ie}=40 \mathrm{~A}-2500 \mathrm{~A}$ c. Icn (kapasitas arus pemutusan), spesifikasi standar MCCB digambarkan sebagai berikut Icn $=12 \mathrm{kA}-200$ $\mathrm{kA}$

\section{Saklar}

Saklar ialah sebagai penghubung dan pemutus arus listrik. Dalam instalasi listrik, penghubung dan pemutus arus listrik secara manual disebut dengan 
saklar mekanis diantaranya sakelar togel (toggle swich). Beberapa jenis sakelar togel antara lain :

a. Saklar SPST (Single Pole Single Throw Switch), merupakan saklar yang terdiri dari satu kutub dengan satu arah, yaitu sebagai pemutus dan penghubung saja. Saklar ini hanya digunakan pada motor dengan daya $>1 \mathrm{HP}$.

b. Saklar SPDT (Single Pole Double Throw Switch), merupakan saklar yang terdiri dari satu kutub dengan dua arah hubungan. Saklar ini dapat bekerja sebagai penukar. Dalam pemutusan dan menghubungkan hanya bagian kutub positif atau fasanya saja.

c. Saklar DPST (Double Pole Single Throw Switch), merupakan saklar yang terdiri dari dua kutub dengan satu arah. Jadi hanya dapat menghubung dan memutus saja. Untuk jenis konstruksi putar jenis saklar ini banyak dijumpai pada kotak sekering instalasi rumah (panel hubung bagi yang paling sederhana).

d. Saklar DPDT (Double Pole Double Throw Switch), merupakan saklar yang terdiri dari dua kutub dengan dua arah. Saklar jenis ini dapat digunakan sebagai penukar. Pada instalai motor dapat digunakan sebagai pembalik putaran motor arus arus searah dan dan motor satu fasa. Juga dapat digunakan sebagai pelayanan dua sumber tegangan pada satu motor.

e. Saklar TPST (Three Pole Single Trhow Switch), merupakan saklar dengan satu arah pelayanan. Digunakan untuk motor 3 fasa atau system 3 fasa lainnya.

f. Saklar TPDT (Three Pole Double Trhow Switch), merupakan saklar dengan tiga kutub yang dapat bekerja kedua arah. Saklar ini digunakan pada instalasi motor tiga fasa atau system tiga fasa lainnya. Juga dapat digunakan sebagai pembalik putar motor 3 fasa, layanan motor 3 fasa dari dua sumber dan juga sebagai starter bintang segitiga yang sangat sederhana.

Kemungkinan lainnnya merupakan kemungkinankemungkinan yang akan terjadi di masa yang akan datang. Seperti penambahan beban yang akan mengacu pada kenaikan arus beban sehingga perhitungan KHA penghantar untuk memilih luas penampang penghantar akan berbeda. Drop tegangan maksimum yang diizinkan adalah dua persen untuk penerangan dan lima persen untuk instalasi daya.

\section{Pembumian.}

Pembumian berfungsi untuk menjaga keseimbangan vector tegangan dan arus listrik, mengamankan manusia dan peralatan listrik akibat adanya kebocoran tegangan induksi, serta kesetabilan supalai tegangan listrik. Pembumian dipasang dengan jalan menghubungkan bagian titik netral jaringan listrik dengan tanah. Umumnya tanah mempunyai karakteristik. Nilai resistans jenis tanah $(\Delta t)$ sangat berbeda tergantung pada komposisi tanah. Hal ini dapat dilihat dalam PUIL 1987 atau yang ditunjukkan pada Tabel 3.

Tabel 3 Nilai Rata-Rata Jenis Tanah

\begin{tabular}{|c|l|l|}
\hline No & Jenis Tanah & $\begin{array}{l}\text { Resistans jenis tanah } \Delta \mathrm{t} \\
\text { dalam ohm-m }\end{array}$ \\
\hline 1 & Tanah Rawa & $10 \mathrm{~s} / \mathrm{d} 40$ \\
\hline 2 & $\begin{array}{l}\text { Tanah liat dan tanah } \\
\text { ladang }\end{array}$ & $20 \mathrm{~s} / \mathrm{d} 100$ \\
\hline 3 & Pasir basah & $50 \mathrm{~s} / \mathrm{d} 200$ \\
\hline 4 & Kerikil basah & $200 \mathrm{~s} / \mathrm{d} 300$ \\
\hline 5 & Pasir/kerikil kering & $<1000$ \\
\hline 6 & Tanah berbatu & $2000 \mathrm{~s} / \mathrm{d} 3000$ \\
\hline 7 & $\begin{array}{l}\text { Air laut dan ait } \\
\text { tawar }\end{array}$ & $10 \mathrm{~s} / \mathrm{d} 100$ \\
\hline
\end{tabular}

Nilai-nilai tersebut pada tabel 3 seluruhnya berlaku untuk tanah lembab sampai basah. Pasir kering mutlak atau batu adalah suatu bahan isolasi yang bagus, sama seperti air destilasi. Maka elektrode bumi selalu harus ditanam sedalam mungkin dalam tanah, sehingga dalam musim kering selalu terletak dalam lapisan tanah yang basah.

\section{Resistans Pembumian}

Elektrode bumi ( $\Delta t$ ) tergantung pada jenis dan keadaan tanah serta pada ukuran dan susunan elektrode. Tabel 4 menununjukkan nilai rata-rata dari resistans pembumian untuk elektrode bumi.

Tabel 4 Nilai Rata-Tata dari Resistans Pembumian untuk Elektrode Bumi

\begin{tabular}{|c|c|c|c|}
\hline $\begin{array}{c}\text { Jenis } \\
\text { elektro } \\
\text { de }\end{array}$ & $\begin{array}{c}\text { Panjang } \\
\text { pita/pengahant } \\
\text { ar }\end{array}$ & $\begin{array}{c}\text { Panjang batang } \\
\text { mipa atau pipa }\end{array}$ & $\begin{array}{c}\text { Pelat vertikal } \\
\text { sisi 1m dalam } \\
\text { tanah }\end{array}$ \\
\hline $\begin{array}{c}\text { Resista } \\
\text { ns }\end{array}$ & $\begin{array}{c}10 \mathrm{~m} 25 \mathrm{~m} \\
50 \mathrm{~m} 100 \mathrm{~m}\end{array}$ & $\begin{array}{c}1 \mathrm{~m} 2 \mathrm{~m} \\
\text { Pembu } 5 \mathrm{~m}\end{array}$ & $0,5 \times 1 \mathrm{~m} 1 \times 1 \mathrm{~m}$ \\
\cline { 2 - 5 } mian & $20 \quad 10$ & 7040 & 3525 \\
\hline
\end{tabular}

Pengukuran Resistans Jenis Tanah $\Delta \mathrm{t}$

Memperoleh nilai tahanan jenis tanah yang akurat diperlukan pengukuran secara langsung pada lokasi. Jika diperlukan di lapangan harus disiapkan hubungan atau koneksi yang mudah dilepas untuk dapat diadakan pengukuran pada tiap-tiap elektrode. Dalam tingkat perencanaan suatu sistim pembumian dengan elektrode bumi adalah sangat bermanfaat bila dianalisa terlebih dahulu dengan bantuan resistans jenis tanah supaya mendapat besarnya spesifikasi yang diperlukan.

Tabel 5 memperlihatkan persamaan pendekatan untuk resistans pembumian $\mathrm{R}$ suatu elektrode bumi untuk beberapa susunan elektrode bumi. Resistans pembumian Rt suatu elektrode adalah resistans dari lapisan tanah antara elektrode bumi atau sistim pembumian dan bumi acuan/referens. 
Tabel 5 Pendekatan resistans pembumian untuk macam elektrode bumi

\begin{tabular}{|c|c|c|}
\hline Jenis elektrode & $\begin{array}{c}\text { Perhitungan } \\
\text { cepat }\end{array}$ & $\begin{array}{c}\text { Perbandingan } \\
\text { pendekatan }\end{array}$ \\
\hline \multirow{2}{*}{ Batang } & $\begin{array}{c}\mathrm{Rbt}=(\Delta \mathrm{t} / 2 \Delta \\
\mathrm{L}) \mathrm{x}(\ln 4 \mathrm{~L} / \mathrm{d})\end{array}$ & $\begin{array}{c}\mathrm{pada} \mathrm{L}<10 \mathrm{~m} ; \\
\mathrm{Rbt}=\Delta \mathrm{t} / \mathrm{L}\end{array}$ \\
\hline & & $\mathrm{pada} \mathrm{L}>10 \mathrm{~m} ;$ \\
& & $\mathrm{Rbt}=1,5 \Delta \mathrm{t} / \mathrm{L}$ \\
\hline \multirow{2}{*}{ Pita } & $\mathrm{Rpt}=(\Delta \mathrm{t} / \Delta \mathrm{L})$ & $\mathrm{pada} \mathrm{L}<10 \mathrm{~m} ;$ \\
& $\mathrm{xpt}(\ln 2 \mathrm{~L} / \mathrm{d})$ & $\mathrm{Rpt}=2 \mathrm{t} / \mathrm{L}$ \\
\hline & & $\mathrm{pada} \mathrm{L}>10 \mathrm{~m} ;$ \\
& & $\mathrm{Rpt}=3 \Delta \mathrm{t} / \mathrm{L}$ \\
\hline
\end{tabular}

Di lapangan atau lokasi sering dilaksanakan dua cara pengukuran untuk menentukan tahanan jenis tanah untuk memperoleh perubahan dalam lapisan tanah.

1. Pengukuran dengan elektrode ukur yang tetap

Satu elektrode ukur, panjang $1 \mathrm{~m}$ ditanamkan tegak lurus dalam lapisan tanah. Dengan alat ukur jembatan-tahanan, diukur tahanan jenis tanah dalam daerah antara permukaan lapisan tanah dan dalamnya pemasukan elektrode tersebut. Analisa untuk tahanan Pembumian batang adalah :

$$
\text { ( 1) ) . 4( } \ln (\text { ) . . 2. ( dL x L t Rt } \square \square \square
$$

di mana : $R t=$ tahanan bentang suatu elektrode dalam (ohm), $\Delta t=$ tahanan jenis tanah dalam ( ohm-meter), $\mathrm{L}=$ panjang elektrode batang dalam $(\mathrm{m}), \mathrm{d}=$ jari-jari batang elektrode dalam ( $\mathrm{m}$ ) $\ln =$ logarithmus (dasar $\mathrm{e}=2.7182818$ ).

\section{Cara mengukur Pembumian menurut metode Von Werner}

Cara mengukur resistans jenis tanah dengan digunakan 4-batang acuan yang dimasukkan dalam tanah dengan jarak a sepanjang satu garis lurus yang sama dan dihubungkan ke alat ukur resistans pembumian. Hal ini dapat dilihat pada Gambar 2.

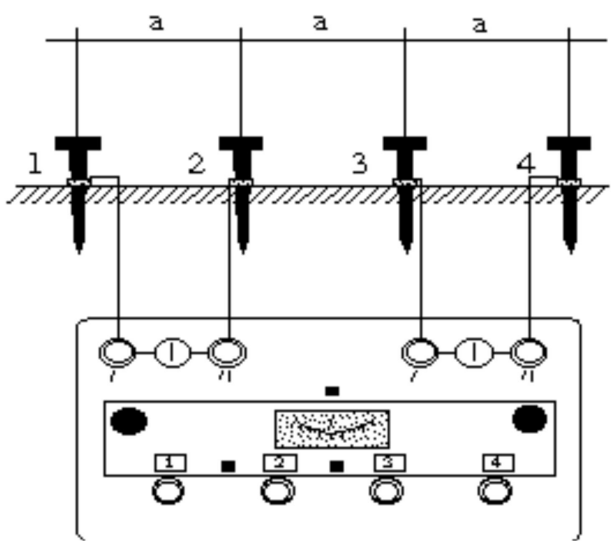

Gambar 3 Cara Pengukuran Pembumian dengan Metode 4 batang elektroda

Pada ujung-ujung luar batang elektrode 1 dan 4 dialirkan arus dan pada bagian dalam dari batang elektrode 2 dan 3 diukur susut tegangan dalam lapisan tanah. Dari hasil pengukuran perbandingan jembatan dapat dibaca nilai tahanan $\mathrm{R}$, maka resistans jenis tanah dapat dihitung dengan pendekatan:

$$
\text { ................. (3) Rt aQt ...2 } \Delta t \Delta t
$$

Bila jarak a dalam $\mathrm{m}$ dan $\mathrm{R}$ dalam ohm, maka terdapat resistans jenis tanah dalam ohm-m yang diukur di sini bukan resistans jenis tanah, hanya resistans jenis tanah semu. Cara atau metode ukur sesuai Von Werner ini hanya dapat mengukur lapisan tanah sampai jarak sedalam a dari elektrode acuan. Dengan merubah-rubah jarak a dapat ditemukan nilai tahanan jenis tanah dalam beberapa lapisan tanah. Seperti telah diterangkan sebelumnya lembab tanah sangat mempengaruhi resistans pembumian. Dalam musim panas dengan terik panas yang panjang, lapisan tanah sangat kering. Bila diadakan pengukuran dalam periode musim kering tersebut harus ditanam elektrode acuan yang lebih panjang untuk menembus dalam lapisan yang basah, atau daerah lapisan tanah sekitar elektrode acuan harus dibasahinya.

Pengukuran resistansi pembumian

Mengukur resistansi pembumian suatu elektrode bumi dapat dilaksanakan menurut proses pengukur arus-tegangan atau dengan alat ukur pembumian menurut pengukuran cara kompensasi:

Pengukuran dengan metode ukur arus tegangan dalam jaringan dengan titik bintang (netral) yang dibumikan sesuai PUIL 2000 Pasal 323, Penghantar bumi dari elektrode bumi RA yang akan diukur dihubung dengan konduktor fase L melalui resistans yang dapat diatur dari $1000 \mathrm{ohm}$ sampai $2000 \mathrm{ohm} \mathrm{di}$ belakang gawai pengaman dalam sirkuit amperemeter. Hal ini dapat dilihat pada Gambar 3 berikut.

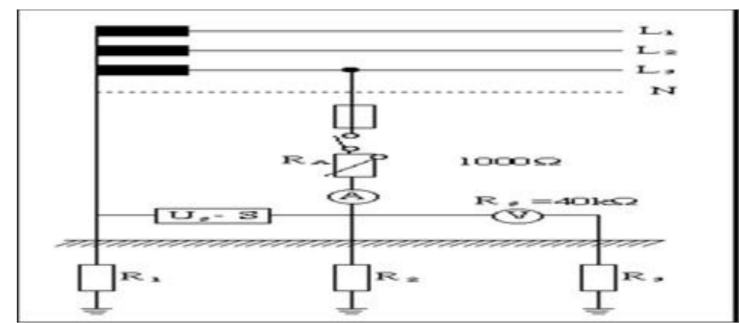

Gambar 4 Pengukuran resistansi pembumian

Dalam sirkuit tersebut dipasang juga voltmeter dengan tahanan internal R1 dari kira-kira $40 \mathrm{k}-\mathrm{ohm}$, di mana diukur tegangan antara elektrode acuan dan elektrode bumi bantu dengan jarak $20 \mathrm{ohm}$.

Kekurangan dari metode ini adalah:

a. Tegangan ukur antara elektrode bumi bantu dan RA tak boleh melebihi tegangan sentuh yang diizinkan, karena dapat terjadi kecelakaan,

b. Hanya dapat dilaksanakan dalam jaringan di mana titik netral langsung dibumikan (lihat a), karena bila terdapat arus bocor kecil yang mengalir ke bumi, dapat menimbulkan susut tegangan antara RA dan 
RS, sehingga terdapat hasil pengukuran yang tak tepat.

Lampu Listrik adalah suatu perangkat yang dapat menghasilkan cahaya saat dialiri arus listrik. Arus listrik yang dimaksud ini dapat berasal tenaga listrik yang dihasilkan oleh pembangkit listrik terpusat (Centrally Generated Electric Power) seperti PLN dan Genset ataupun tenaga listrik yang dihasilkan oleh Baterai dan Aki.

Di zaman modern ini, Lampu Listrik telah menjadi salah satu alat listrik yang paling penting bagi kehidupan manusia. Dengan adanya lampu listrik, kita dapat melakukan berbagai kegiatan pada malam hari, memperindah Interior maupun Eksterior rumah, penerang ruangan yang gelap ataupun sebagai Indikator tanda-tanda bahaya. Sebelum ditemukan lampu listrik, manusia pada saat itu menggunakan lilin, lampu minyak dan api unggun sebagai alat penerang pada malam hari.

Banyak yang beranggapan bahwa yang paling pertama kali menemukan Lampu Listrik adalah Thomas Alva Edison (1847-1931) dari Amerika Serikat. Anggapan tersebut tidak sepenuhnya benar, karena sebelum Thomas Alva Edison, telah banyak ilmuwan yang menciptakan berbagai jenis lampu listrik dengan bermacam-macam bahan dan teknik, akan tetapi penemuan-penemuan mereka tersebut tidak praktis, tidak bertahan lama, boros listrik dan harganya pun sangat mahal.

Namun, Thomas Alva Edison merupakan ilmuwan pertama yang menemukan lampu pijar (Incandescent lamp) komersial yang dapat tahan lama, penggunaan listrik yang lebih hemat dan juga dengan bahan yang lebih murah. Lampu Listrik temuan Thomas Alva Edison inilah yang digunakan oleh khalayak ramai dan hingga saat ini kita masih menikmati hasil penemuannya ini. Lampu Pijar pertama yang ditemukan oleh Thomas Alva Edison pada tanggal 22 Oktober 1879 hanya dapat bertahan hingga 13,5 jam.

\section{Simbol-simbol Lampu}
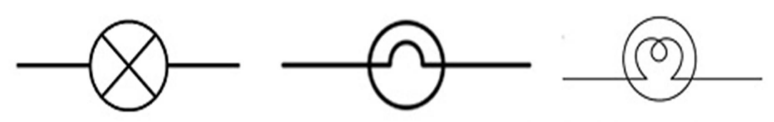

teknikelektronika.com

Gambar 5 Simbol Lampu Listrik Dalam Elektronika

Jenis-Jenis Lampu Listrik

Seiring dengan perkembangan Teknologi, Lampu Listrik juga telah mengalami berbagai perbaikan dan kemajuan. Teknologi Lampu Listrik bukan saja Lampu Pijar yang ditemukan oleh Thomas Alva Edison saja namun sudah terdiri dari berbagai jenis dan Teknologi. Pada dasarnya, Lampu Listrik dapat dikategorikan dalam Tiga jenis yaitu Incandescent
Lamp (Lampu Pijar), Gas-discharge Lamp (Lampu Lucutan Gas) dan Light Emitting Diode (Lampu LED).

Berikut ini adalah Tiga jenis utama Lampu Listrik yang dimaksud :

1) Lampu Pijar (Incandescent lamp)

Lampu Pijar atau disebut juga Incandescent Lamp adalah jenis lampu listrik yang menghasilkan cahaya dengan cara memanaskan Kawat Filamen di dalam bola kaca yang diisi dengan gas tertentu seperti nitrogen, argon, kripton atau hidrogen. Kita dapat menemukan Lampu Pijar dalam berbagai pilihan Tegangan listrik yaitu Tegangan listrik yang berkisar dari 1,5V hingga $300 \mathrm{~V}$.

2) Lampu Lucutan Gas (Gas-discharge Lamp)

Gas-discharge Lamp atau Lampu Lucutan Gas adalah Lampu Listrik yang dapat menghasilkan cahaya dengan mengirimkan lucutan Elektris melalui gas yang terionisasi. Gas-gas yang digunakan adalah gas mulia seperti argon, neon, kripton dan xenon. Gas-discharge Lamp ini juga memakai bahan-bahan tambahan seperti Merkuri, Natrium dan Halida logam. Lampu jenis ini diantaranya adalah lampu Fluorescent, Lampu Neon, Lampu Xenon Arc dan Mercury Vapor Lamp.

3) Lampu LED (Light Emitting Diode)

Lampu LED adalah Lampu listrik yang menggunakan komponen elektronika LED sebagai sumber cahayanya. LED adalah Dioda yang dapat memancarkan cahaya monokromatik ketika diberikan Tegangan maju. Lampu listrik jenis LED ini memiliki banyak kelebihan seperti lebih hemat energi, lebih tahan lama dan tidak mengandung bahan berbahaya (contohnya Merkuri). Namun Harga Lampu LED lebih mahal jika dibanding dengan Lampu Fluorescent dan Lampu Pijar sehingga penggunaannya masih sangat terbatas. Lampu LED memiliki daya tahan hingga 25.000 jam atau 2,5 kali lipat lebih tahan lama dari Lampu Fluorescent.

\section{Metodologi}

Perencanaan awal dilakukan survey kelokasi gedung semua ruangan, kemudian dilakukan pengukuran luas ruangan dan tinggi plafon. Setelah survey dilakukan analisis kuat penerangan cahaya serta jenis kabel serta jenis lampu yang digunakan, dan rencana gambar detail elektrikal engineering. Setelah gambar dan analisis selesai dilakukan rencana dapat direalisasikan.

\section{HASIL DAN PEMBAHASAN}

Berdasarkan hasil survei lokasi yang telah dilakukan oleh tim PT. Basuh Power Electric, pada tanggal 5 Pebruari 2014, diperoleh data informasi gedung seperti diperlihatkan pada Gambar 6 


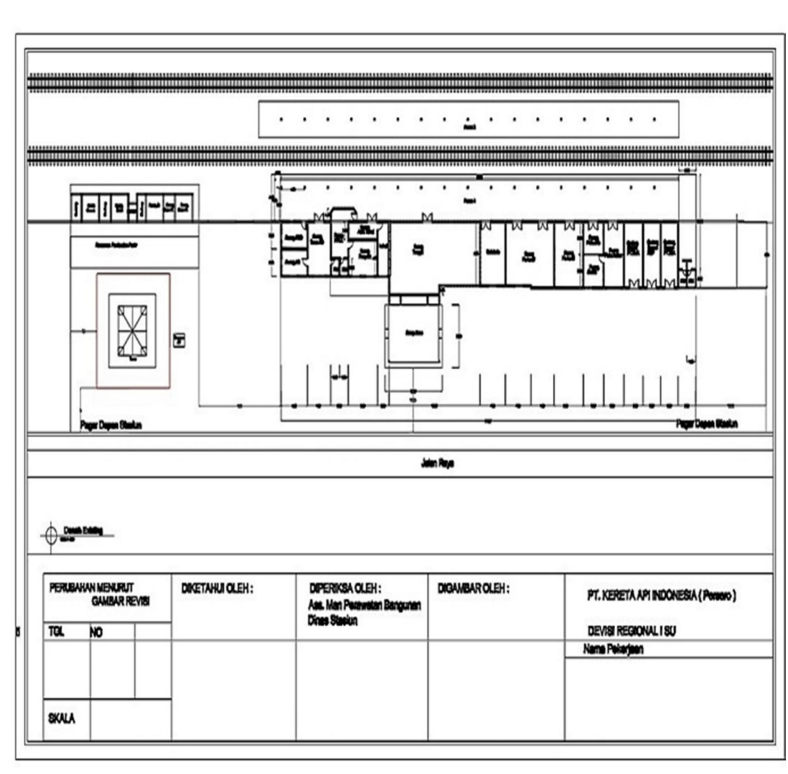

Gambar 6 Denah Lokasi Stasiun Tebing Tinggi

Keterangan ukuran bangunan :

Panjang : 83 Meter

Lebar: 8 Meter

Tinggi: 9 meter

\section{Analisis Kebutuhan Lampu}

Kebutuhan jumlah lampu yang digunakan sangat ditentukan oleh kuat penerangan cahaya. Berdasarkan standara PUIL kuat penerangan cahaya untuk pabrik sebesar 100 hingga 250 lux. Mengacu kuat penerangan cahaya tersebut, kemudian dapat memilih jenis lampu yang akan digunakan. Pemilihan jenis lampu sebaiknya memperhatikan kuat intensitas penerangan cahaya, faktor kerja dan besar konsumsi energi listrik serta lama usia lampu. Sebagai analisis diberikan contoh sebagai berikut, kuat penerangan cahaya (Standar) : 100 lux hingga 250 lux. Jenis lampu yang digunakan lampu LED Hannochs dan TL Hannochs Spesifikasi Tegangan, Daya $(P): 220$ Volt, 150 Watt.

\section{Dengan Keterangan :}

-Kuat penerangan cahaya $(I)$ : 12.000 lumen

-Umur lampu $(t)$ : 26.000 jam.

Analisis Kuat penerangan cahaya Pada Gedung

Sebagai asusmsi dasar kuat intensitas penerangan gedung direncanakan sama besarnya yaitu 250 lux, ukuran gedung $=(83 \times 8 \times 9) \mathrm{m}$, Langkah analisi dilakukan menggunakan 1 unit lampu terlebih dahulu, dalam hal ini dipilih 150 watt untuk Gedung, dengan lumen 9.500 (sesuai spesifikasi lampu LED Hannochs dan TL Hannochs). Sehingga analisisnya Kuat intensitas penerang lampu diatas permukaan lantai dengan ketinggian ( $\mathrm{t}$ ), mengacu persamaan (5)
$E=117,28 \operatorname{lux}$

Lampu (n)

Tinggi $(\mathrm{t})$

Kuat Intensitas Cahaya (E)

Sehingga analisisnya Kuat intensitas penerang lampu diatas permukaan lantai dengan ketinggian (d), mengacu persamaan (5)

$E=61,22 \operatorname{lux}$

Itensitas cahaya (I) ; 9500 lumen

Tinggi lampu dari lantai $(d): 9$ meter

Maka kuat intensitas cahaya (E): 117,28 lux

Lampu (n)

Tinggi (t)

Kuat Intensitas Cahaya (E)

Kuat penerangan cahaya pada setiap ruangan di gedung $=117,28$ lux, tetapi masih belum memenuhi standar PUIL untuk pabrik, sehingga kuat penerangan tersebut masih perlu dinaikan, dengan jalan menambah jumlah lampu dan memperhatikan lumenitas dari lampu.

Analisis Kebutuhan Jumlah Lampu Pada Gedung

Menurut SNI secara umum, tipe daya pencahayaan maksimum untuk ruang kantor/ industri biasanya adalah 15 watt/ $\mathrm{m}^{2}$. Selanjutnya cara mengetahui titik-titik lampu pada setiap ruangan yang ada di gedung. Penentuan titik-titik lampu akan ditentukan sebagai berikut :

$$
\mathrm{N}=(\mathrm{E} \times \mathrm{L} \times \mathrm{W} \times) /(\mathrm{Q} \times \mathrm{LLF} \times \mathrm{CU} \times \mathrm{n})
$$

Dengan keterangan :

$\begin{array}{ll}\mathrm{N} & =\text { Jumlah titik lampu } \\ \mathrm{E} & =\text { Kuat penerangan (Lux), gedung } \\ & \text { standar } 100 \text { lux }-250 \text { lux } \\ \mathrm{L} & =\text { Panjang ruangan } \\ \mathrm{W} & =\text { Lebar ruangan } \\ \mathrm{Q} & =\text { Total lumen lampu }(w \times \text { L } / w: \text { daya } \\ & \text { lampu } x \text { luminous efficacy lamp } \\ & \text { dapat dilihat pada box lampu yang } \\ & \text { dibeli) }\end{array}$


(Studi Kasus Stasiun Tebing Tinggi)

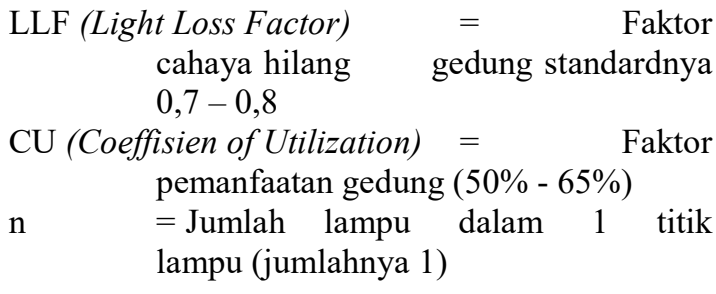

Contoh perhitungannya :

Untuk ruang loket sebesar $4 \mathrm{~m} \times 8 \mathrm{~m}$ dan jenis lampu yang digunakan adalah tipe TL Hannochs 25 watt, berapa titik lamou yang harus dipasang?

Diketahui :

E : Karena ruang loket butuh lebih terang
dengan nilainya 250 lux.

L : 8m; W : 4m; LLF : 0,8: CU : 65\%; $\mathrm{n}: 1$

Q : Untuk lampu TL Hannochs 25 watt mempunyai Luminous Efficacy dengan Lamp sebesar $61 \mathrm{Lm} / \mathrm{w}$ (yang ada di box lampu)

$\mathrm{Q}: \mathrm{w} \times \mathrm{Lm} / \mathrm{w}: 25$ x $61: 1.525$ lumen

Jawab :

$$
\begin{aligned}
& \mathrm{N}=(\mathrm{E} \times \mathrm{L} \times \mathrm{W}) /(\mathrm{Q} \times \mathrm{LLF} \times \mathrm{CU} \times \mathrm{n}) \\
& \mathrm{N}=(250 \times 83 \times 8) /(1525 \times 0,8 \times 65 \% \times 1) \\
& \mathrm{N}=166000 / 793 \\
& \mathrm{~N}=209,33
\end{aligned}
$$

Jadi, jumlah titik lampu pada setiap ruangan digedung adalah 209 buah.

\section{KESIMPULAN}

Berdasarkan hasil dan bahasan, maka dapat ditarik kesimpulan bahwa Untuk mensurvey hasil penelitian dilapangan maka diperlukannya alat untuk mengukur intensitas cahaya yaitu Lux Meter. Jumlah lampu yang dibutuhkan untuk menghasilkan kuat penerangan cahaya disetiap ruangan pada gedung stasiun tebing tinggi dengan ukuran 250 lux dengan menggunakan lampu LED Hannochs dan TL Hannochs yang sebanyak 209 unit sehingga menghasilkan kuat penerangan cahaya 250 lux. Jumlah kabel yang dibutuhkan terdiri kabel penerangan jenis NYM 3x2,5 mm2, sebanyak 50 roll, dan kabel tenaga NYY 4 × 6 mm2 sebanyak 2 roll.

\section{DAFTAR PUSTAKA}

[1] Indra Mustika R. P., Chris Timotius K., Hasbullah Program Studi, MARET 2013 "Aplikasi Perencanaan Perhitungan Instalasi Listrik Penerangan Menggunakan Sistem Pakar" Pendidikan Teknik Elektro FPTK UPI ISSN 1412 - 3762 http://jurnal.upi.edu/electrans ELECTRANS, VOL.12, NO.1, , 49- 58

[2] Agung widayat1, Dr Belyamin2, Drs Kusnaedi, 2019 "Analisis Kualitas Daya Listrik Dengan Menggunakan Analisa Distribusi Beban 3 Fasa", Prosiding Seminar Nasional Teknik Elektro Volume 4 Tahun 132,ST,MT3 Program Magister Terapan ,Teknik Elektro ,Politeknik Negeri Jakarta( PNJ),

[3] Joslen Sinaga, "Perancangan Instalasi Listrik Pada Rumah Toko Tiga Lantai Dengan Daya" 12 KW Oleh: Universitas Darma Agung, Medan

[4] Iksan Santoso, 2014, "Perancangan Instalasi Listrik Pada Blok Pasar Modern Dan Apartemen Di Gedung Kawasan Pasar Terpadu Blimbing Malang”, Jurnal Jurusan Teknik Elektro Kementerian Pendidikan Dan Kebudayaan Universitas Brawijaya Fakultas Teknik Malang

[5] Khahfi Muhammad Madro'i, Setyo Supratno, Putra Wisnu Agung Sucipto, "Simulasi Perhitungan Kebutuhan Penerangan Ruangan Dan Penentuan Luas Penampang Kabel Berbasis Sistem Pakar" Program Studi Teknik Elektro Fakultas Teknik Universitas Islam "45" Bekasi JREC Journal of Electrical and Electronics Vol. 4 No. 2

[6] http://eprints.umm.ac.id/40216/3/BAB\%202

[7] https://webteknisi.com/karakteristik-dan-prinsipkerja-mcb-miniature-circuit-breaker/

[8] https://dunialistrik.wordpress.com/2017/07/18/sis tem-instalasi-tenaga-listrik-tegangan-menengahdan-tegangan-rendah-pada-bangunangedung/

[9] https://agesa21.wordpress.com/2014/03/24/rangk ain-ekivalen-transformer/

[10] https://www.hasanbasri93.com/2014/12/luxmeter-alat-pengukur-cahaya.html?m=1

[11] http://engineeringbuilding.com/2011/09/menetuk an-jumlah-titik-lampu-dalam.html? $\mathrm{m}=1$

[12] https://teknikelektronika.com/jenis-jenis-lampulistrik-simbol-lampu/ 